\title{
Transporte e destinação dos RCC gerados no Município de São Paulo: a importância da qualidade das informações disponibilizadas aos usuários
}

\section{Transportation and destination of construction waste generated in the city of São Paulo: the importance of the quality of the information made available to users}

Transporte y eliminación de los residuos de construcción generados en Sao Paulo: la importancia de la calidad de la información disponible para los usuários

Pedro Lombardi Filho' Ednilson Viana ${ }^{2}$ Lucianne Mattioli ${ }^{3}$ Gabriella Manolio Pissiguelli ${ }^{4}$

${ }^{1}$ Mestrando no Programa de Pós-Graduação em Ambiente, Saúde e Sustentabilidade da Faculdade de Saúde Pública (USP). Pós-Graduado em Gestão de Tecnologias Ambientais- MBA-USP. Graduado em Engenharia Civil pela Escola Politécnica (USP). E-mail: pedro.lombardi.filho@terra.com.br

${ }^{2}$ Biólogo pela Unesp de São José do Rio Preto, SP. Pós-doutor pela Universidade Nova de Lisboa. Professor no curso de Gestão Ambiental da Escola de Artes, Ciências e Humanidades - EACH, da Universidade de São Paulo (USP). E-mail: ednilson.viana@gmail.com

${ }^{3}$ Graduada no Curso de Bacharelado em Gestão Ambiental da Escola de Artes, Ciências e Humanidades - EACH, da Universidade de São Paulo (USP).E-mail: lu_matti@hotmail.com

${ }^{4}$ Graduada no Curso de Bacharelado em Gestão Ambiental -USP da Escola de Artes, Ciências e Humanidades - EACH, da Universidade de São

Paulo. E-mail: gabi.mpi@hotmail.com 
Resumo: O presente estudo teve como objetivo uma discussão sobre a qualidade das informações disponibilizadas pela Prefeitura Municipal de São Paulo (PMSP) aos usuários geradores de resíduos da Construção Civil (RCC). Nessa análise, foram utilizadas como base as informações disponibilizadas pela PMSP, Secretaria Municipal de Serviços (SES) e a Autoridade Municipal de Limpeza Urbana (AMLURB) em seus canais de comunicação com os usuários do sistema de transporte e destinação de RCC gerados no referido município. Os dados foram focados no sistema de transporte via caçambas estacionárias, nas áreas de transbordo e triagem (ATTs) e áreas de entrega voluntárias de pequenos volumes (ECOPONTOS), voltadas aos geradores de pequenos volumes de RCC. As listas disponíveis aos usuários, principalmente aos geradores de pequenos volumes, não estão claras e são conflitantes, o que dificulta que eles se integrem de fato ao sistema de gestão de RCC de forma participativa e sustentável.

Palavras-chave: resíduos da construção civil; áreas de transbordo e triagem; ecopontos; caçambas.

Abstract: The present study aimed to discuss the quality of information provided by the City Hall of São Paulo (PMSP) to the users who generate Civil Construction Waste (RCC). The information provided by the PMSP, by the Municipal Service Secretariat (SES) and by the Municipal Urban Cleaning Authority (AMLURB) on their communication channels with the users of the transportation system and the destination of RCC generated in the aforesaid city was used as the basis of this analysis. The data were focused on the transportation system, via construction waste container, in the areas of transshipment and sorting (ATTS) and voluntary small volume delivery areas (ECOPONTOS), focused on the small volume RCC generators. The lists available to users, especially to small volume generators, are not clear and are conflicting which makes it difficult for them to effectively integrate into the RCC management system in a participatory and sustainable way.

Key words: construction waste; transhipment and sorting areas; ecopontos; containers.

Resumen: Este estudio tuvo como objetivo un análisis de la calidad de la información proporcionada por el Municipio de Sao Paulo (Sao Paulo Gobierno Municipal) a los generadores de residuos de la Construcción (RCC). Se utilizó este análisis basado en la información proporcionada por Sao Paulo Gobierno Municipal (PMSF), los servicios municipales (SES) y la Autoridad Municipal de Limpieza Urbana (AMLURB) en sus canales de comunicación con los usuarios del sistema de transporte y distribución de RCC generados en ese municipio. Los datos se centraron en el sistema de transporte, a través de contenedores de residuos de construcción, áreas de transbordo y cribado (ATTS) y las áreas de prestación voluntaria de volúmenes pequeños (ecopontos), dirigidos a la generación de pequeños volúmenes de RCC. Las listas que los usuarios, especialmente los generadores de pequeños volúmenes de RCC no son claras y están en conflicto, por lo que es difícil para ellos, generadores de grandes o pequeños se integran, de hecho, el sistema de gestión del RCC de forma participativa y sostenible.

Palabras clave: residuos de la construcción; Trasbordo y clasificación de áreas; ecopontos; contenedores de residuos de construcción. 


\section{INTRODUÇÃO}

Os resíduos da construção civil (RCC), conforme a Política Nacional de Resíduos Sólidos (PNRS) (BRASIL, 2010), são aqueles gerados nas construções, reformas, reparos e demolições de obras de construção civil, incluindo os originados da preparação e escavação de terrenos para obras civis. Esses resíduos representam aproximadamente 50 \% em massa dos resíduos sólidos urbanos gerados no Brasil (ANGULO et al., 2004) e 50\% dos resíduos sólidos gerados na cidade de São Paulo (BRASIL, 2012).

De acordo com a resolução CONAMA n. 307/2002, e alterações feitas pelas resoluções Conama 431/2011, 469/2015, 348/2004 e 448/2012, os RCC são classificados em quatro categorias da seguinte forma:

Classe A- são os resíduos reutilizáveis ou recicláveis como agregados, tais como:

a) de construção, demolição, reformas e reparos de pavimentação e de outras obras de infraestrutura, inclusive solos provenientes de terraplanagem;

b) de construção, demolição, reformas e reparos de edificações: componentes cerâmicos (tijolos, blocos, telhas, placas de revestimento etc.), argamassa e concreto;

c) de processo de fabricação e/ou demolição de peças pré-moldadas em concreto (blocos, tubos, meios-fios etc.) produzidas nos canteiros de obras.

Classe B - são os resíduos recicláveis para outras destinações, tais como: plásticos, papel/papelão, metais, vidros, madeiras, gessos, embalagens vazias de tintas imobiliárias e outros. A Resolução do CONAMA n. 431/2011 alterou o artigo 3ㅇ da Resolução CONAMA n. 307/2002, mudando o gesso da classe C para a classe B. A CONAMA n. 469/2015, por sua vez, incluiu na classe $B$ as embalagens vazias de 
tintas imobiliárias cujo recipiente apresenta apenas filme seco de tinta em seu revestimento interno, sem acúmulo de resíduo de tinta líquida e ainda determina que as embalagens de tintas usadas na construção civil serão submetidas ao sistema de logística reversa, conforme requisitos da Lei n. 12.305/2010, que contempla a destinação ambientalmente adequada dos resíduos de tintas presentes nas embalagens. Classe C- são os resíduos para os quais não foram desenvolvidas tecnologias ou aplicações economicamente viáveis que permitam a sua reciclagem/recuperação.

Classe D-são os resíduos perigosos oriundos do processo de construção, tais como: tintas, solventes, óleos e amianto, que requerem cuidados especiais na sua disposição ou aqueles contaminados oriundos de demolições, reformas e reparos de clínicas radiológicas, instalações industriais e outros. A Resolução do CONAMA n. 348/2004 inclui o amianto como resíduo classe $D$, o qual requer cuidados especiais na sua disposição. É importante ressaltar que a Resolução CONAMA n.

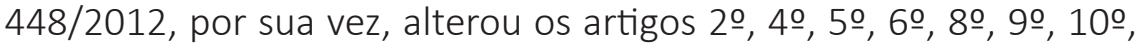
11 을 e revogou os artigos 7ㅇ, 12ㅇ e 13‥ As alterações nos referidos artigos referiram-se à redefinição de alguns conceitos, a uma nova redação de vários desses artigos e o acréscimo de outros elementos importantes na gestão dos RCC (SCHIMITZ; VIANA, 2015).

Com relação às redefinições conceituais feitas pela Resolução CONAMA n. 448/2012, estas referiram-se às Área de transbordo e triagem (ATTs) de RCC e resíduos volumosos, aos aterros de resíduos classe $A$, ao gerenciamento de resíduos sólidos e gestão integrada. Os principais acréscimos foram realizados nos artigos $4^{\circ}$ e $5^{\circ}$, Assim, o artigo $4^{\circ}$ inclui o tratamento dos resíduos sólidos e a disposição ambientalmente adequada dos rejeitos como elemento da gestão dos RCC; o artigo $5^{\circ}$ estabelece que os Planos de Gestão de RCC nas suas diversas esferas de abrangência devem ser elaborados em conformidade com os Planos Municipais de Gestão Integrada de Resíduos Sólidos. 


\subsection{A geração dos RCC}

Ao serem gerados, os RCC devem ser acondicionados em seu local de origem, para depois serem transportados e destinados. Esse fluxo envolve um conjunto de atores como os geradores, transportadores, receptores e o poder público como agente fiscalizador, como mostra a Figura 1.

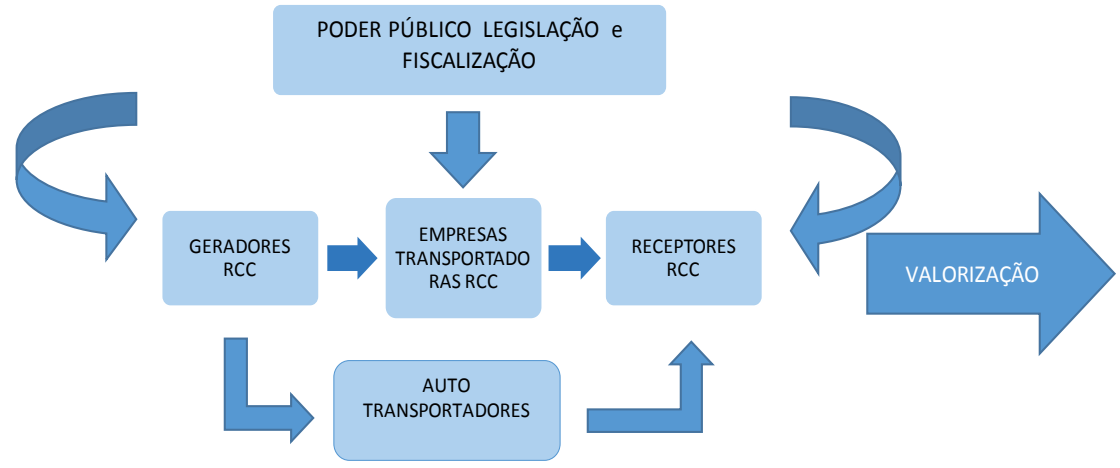

Figura 1 - Descrição do fluxo do processo de gestão dos RCC e os atores envolvidos

A relação entre os atores desse processo de gestão é muito importante, pois cada qual tem a sua função e a sua responsabilidade. O gerador, de acordo com o princípio básico previsto na PNRS, tem a função de reduzir ao máximo a produção de RCC e, conforme o volume gerado, segregar, transportar e destinar aos locais estabelecidos e legalizados pelos órgãos responsáveis. O fluxo do processo, do início ao fim, deve sempre estar sob a fiscalização do poder público.

Nesse contexto de responsabilidades, atribuído pela legislação em vigor, a informação veiculada ao gerador é de grande importância e deve envolver todas as etapas do gerenciamento dos RCC, mas principalmente o transporte e as áreas de destinação/recepção des- 
tes. Para a cidade de São Paulo, foco deste estudo, merece atenção a abordagem de algumas dessas etapas que desenham o gerenciamento dos RCC na cidade, ampliam a visão sobre o sistema de informações oferecidos pela prefeitura e as conexões com os usuários, tanto aos geradores de grandes volumes como aos pequenos também.

\subsection{0 transporte de RCC}

O transporte e a coleta de resíduos da construção civil, no Brasil, passou por muitas alterações ao longo do tempo. Segundo Pinto (1999), os grandes volumes de RCC eram transportados até o final da década de 1980 via caminhões com carrocerias basculantes ou de madeira. Porém, dependendo do volume, era muito significativa a presença de outros tipos de coletores que operavam com veículos isolados como "caminhonetes" e carroças à tração animal.

A atividade de transporte via caçambas estacionárias com o uso de caminhões poliguindastes teve seu crescimento acelerado nos anos 1990, o que agilizou muito o descarte de RCC das obras e, ao mesmo tempo, gerou impactos socioeconômicos ambientais nas cidades. Esse impactos, no município de São Paulo, são decorrentes do uso indiscriminado das caçambas estacionárias pelos usuários geradores, transportadores e população, além da lentidão do processo de publicação de uma legislação que regulamentasse o uso dessas caçambas no espaço urbano, fato esse que só foi ocorrer mais tarde pelo Decreto Municipal 37.952 de 10 de maio de 1999 (SÃO PAULO, 1999).

Atualmente o sistema de geração, transporte, destinação e fiscalização de RCC no Município de São Paulo depende da classe e volume dos RCC gerados. Para pequenos volumes de até $50 \mathrm{Kg}$ diários de resíduos classe $A$, a própria Prefeitura Municipal faz a coleta e transporte, desde que estes estejam bem acondicionados, conforme 
a Lei Municipal n. 13.478 de 2002, atualizada pela Lei Municipal n. 13.522, de 19 de fevereiro de 2003, em seu artigo 22 .

Os pequenos volumes, de até $1,0 \mathrm{~m}^{3}$ de RCC classes $\mathrm{A}, \mathrm{B}$ e $\mathrm{C}$, devem ser destinados (autotransportados) aos pontos de entrega voluntários (Ecopontos), distribuídos na cidade de São Paulo, de acordo com o Decreto Municipal n. 42.217 de 24 de julho de 2002, que regulamenta a Lei n. 10.315, de 30 de abril de 1987, referindo-se ao uso de áreas destinadas ao transbordo e triagem de resíduos de construção civil e resíduos volumosos.

Para os grandes volumes, ou seja, acima de $1,0 \mathrm{~m}^{3}$, fica sob a responsabilidade dos geradores contratar o serviço licenciado na PMSP de empresas de caçambas estacionárias, caçambas basculantes instaladas em veículos, carrocerias para carga seca, caçambas ou equipamentos de transporte de terra, conforme o Decreto Municipal n. 46.594, de 3 de novembro de 2005, que regulamenta a coleta, o transporte, o tratamento e a disposição final de resíduos inertes, de que trata a lei n. 13.478, de 30 de dezembro de 2002, com as alterações subsequentes.

Para a contratação dos serviços de transporte de RCC pelos usuários geradores, a Prefeitura Municipal de São Paulo (PMSP), a Secretaria Municipal de Serviços (SES) e a Autoridade Municipal de Limpeza Urbana (AMLURB) disponibilizam, em seus sites, listas das empresas autorizatárias, cadastradas e habilitadas para o transporte de RCC. Para o controle e a fiscalização desse transporte de RCC foi instituído, pelo decreto Municipal n. 42.217 de 25 de julho de 2002 e reformulado pelo Decreto Municipal n. 46.594/2005, o Controle de Trafego de Resíduos (CTR).

O CTR é, portanto, um documento emitido pelo transportador de RCC, que fornece informações sobre gerador, origem, quantidade, descrição dos resíduos e seu destino. O documento é emitido em três vias, uma para cada ator do processo, ou seja, o gerador, o transpor- 
tador e o destinatário. Esse instrumento de fiscalização objetiva o rastreamento dos RCC gerados até o seu destino. Esse sistema, que demonstrou ser pouco efetivo pela própria falta de fiscalização da PMSP, está sendo aprimorado em sua versão online, o CTR eletrônico, que tem a função de monitoramento mais efetivo e possibilitará a rastreabilidade das caçambas em vias públicas.

\subsection{Opções de destino dos RCC gerados no município de São Paulo}

Conforme os parâmetros de classe e volume dos RCC gerados, o sistema implementado pela PMSP disponibiliza locais para a destinação desses resíduos, que podem ser áreas de transbordo e triagem (ATT) ou áreas de entrega voluntária de pequenos volumes (Ecopontos).

\section{a) Áreas de Transbordo e Triagem (ATT)}

Estas áreas são destinadas ao recebimento de resíduos da construção civil classes A, B e C e resíduos volumosos, para triagem, armazenamento temporário dos materiais segregados, eventual transformação e posterior remoção para adequada disposição, evitando danos à saúde pública e ao meio ambiente (SINDICATO DA INDÚSTRIA DA CONSTRUÇÃO CIVIL [SINDUSCON], 2005).

O material recolhido é separado, e o resíduo de origem mineral é encaminhado para aterros de inertes. O rejeito, por sua vez, é levado para aterros sanitários e o resíduo reaproveitável é comercializado (PMSP, 2016a).

Nas ATTs Municipais, regidas pelo Decreto Municipal n. 42.217, de 24 de julho de 2002, não é permitido o recebimento de cargas de resíduos de construção civil constituídas predominantemente por RCC classe D perigosos (tintas, solventes, óleos, resíduos provenientes de instalações industriais e outros). Esses empreendimentos poderão, ainda, realizar a transformação/beneficiamento da fração mineral do 
RCC, necessitando obter, além da licença de funcionamento municipal, a licença de operação junto à Companhia Ambiental do Estado de São Paulo (CETESB).

b) Áreas de entrega voluntárias de pequenos volumes

\section{- Ecopontos}

Os Ecopontos são locais de entrega voluntária para até $1 \mathrm{~m}^{3} \mathrm{de}$ RCC, ou seja, pequenos volumes de RCC, grandes objetos (móveis, podas de árvores etc.) e resíduos recicláveis. Nesses locais, há a restrição ao recebimento de cargas constituídas predominantemente por RCC classes D (tintas, solventes, óleos, resíduos provenientes de instalações industriais e outros). A NBR 15112 (ASSOCIAÇÃO BRASILEIRA DE NORMAS TÉCNICAS [ABNT], 2004a) fixa os requisitos exigíveis para projeto, implantação e operação de áreas de transbordo e triagem de resíduos da construção civil e resíduos volumosos.

Nos Ecopontos, o usuário gerador pode descartar o material gratuitamente em caçambas específicas para cada tipo de resíduo (PMSP, 2016b). Além disso, a sua localização refere-se, preferencialmente, a áreas já degradadas por descarte irregular de entulho e sem comprometimento de suas funções. Essas áreas poderão ser utilizados de forma compartilhada por grupos locais que desenvolvam ações de coleta seletiva de resíduos sólidos recicláveis, de origem domiciliar (SÃO PAULO, 2002a).

\subsection{Os impactos ao meio urbano do município de São Paulo decorrentes do descarte ilegal de RCC}

Um problema recorrente em relação à destinação inadequada de RCC na cidade de São Paulo são os chamados pontos viciados, que se caracterizam pelo acúmulo de um conjunto heterogêneo de resíduos misturados e dispostos em locais impróprios como ruas, beira de córregos e becos. Geralmente iniciam com a deposição de pequenos 
volumes de RCC e logo recebem novas descargas de entulho, resíduos volumosos inservíveis, terra, materiais diversos e até mesmo resíduos domiciliares (PMSP, 2014). Os motivos que levam a esse tipo de conduta são muito variados, mas a dificuldade de acesso à informação sobre como seria a forma adequada e quais as opções melhores para o destino de RCC também podem contribuir para essa realidade.

Pelos dados mais recentes obtidos, o número de pontos viciados na cidade de São Paulo é de 3.345, distribuídos pelo município da seguinte forma (PMSP, 2015):

- PEQUENOS VOLUMES: Até $1 \mathrm{~m}^{3}$, estimativa: 1.146 pontos, originários da ação de Carrinheiros e/ou Munícipes;

- GRANDES VOLUMES: Acima de $1 \mathrm{~m}^{3}$, estimativa: 2.199 pontos, originários da ação de transportadores de RCC clandestinos;

Conforme os números de pontos viciados apresentados, é possível ter uma noção do tamanho do problema, visto que os pontos de descarte ilegais de RCC, segundo Jacobi e Besen (2011), quando ocorrem em ruas, avenidas e praças, provocam enchentes e privam a população de espaços que poderiam ser destinados para lazer e recreação. Além disso, os RCC dispostos inadequadamente poluem o solo, degradam paisagens e constituem uma grave ameaça à saúde coletiva, pois resultam também na atração de resíduos não inertes, ocasionando a proliferação de vetores de doenças e outros efeitos à saúde pública (SCHNEIDER, 2003).

Segundo Paschoalin e Graudenz (2012), o acúmulo desses resíduos torna-se nicho ecológico de diversas espécies de agentes patogênicos, tais como roedores, baratas, moscas, vermes, pernilongos, fungos, vírus, animais entre outros. Esses vetores biológicos podem ser responsáveis pela transmissão de doenças respiratórias, epidérmicas, viroses, intestinais entre outras.

As informações sobre onde encontrar o transporte adequado e confiável para um destino correto são imprescindíveis para a fluidez 
do sistema de gerenciamento dos RCC nas suas etapas de geração, transporte, destinação e fiscalização. O gerador, por sua posição inicial no processo de geração do RCC, determina as quantidades e os tipos (classes) de RCC gerados em sua obra, através da eficiência dos métodos construtivos utilizados, como a qualificação da mão de obra contratada, e ainda pelas decisões pré-executivas como a escolha dos materiais a adotar no acabamento, como exemplo, o uso de tintas imobiliárias à base de água. Esse tipo de atitude reduz a quantidade de RCC classe D perigosos, gerados na obra.

Além da redução dos RCC gerados, o seu transporte e a sua destinação devem ser feitos conforme a legislação vigente e com o menor impacto possível ao meio. Isto é possível quando o gerador consegue visualizar os caminhos de cada tipo de RCC, conforme a sua classe e o seu volume transportado. Portanto os dados disponibilizados pelo poder público devem primar pela organização, facilidade no acesso e na linguagem, proporcionando ao usuário gerador base para a sua participação ativa e consciente no processo.

\section{METODOLOGIA}

Este artigo teve como foco analisar a importância das informações disponibilizadas pela PMSP com relação ao transporte e a destinação dos RCC gerados naquele município. Para tanto, utilizaram-se como base as informações disponibilizadas pela Prefeitura Municipal de São Paulo (PMSP), Secretaria Municipal de Serviços (SES) e a Autoridade Municipal de Limpeza Urbana (AMLURB), em seus canais de comunicação com os usuários do sistema de transporte e destinação de RCC, gerados no referido município.

O eixo principal do trabalho consistiu na busca pelas informações disponibilizadas pelos canais de comunicação, sites da PMSP e da SES/AMLURB, que estabelecem os contatos e o fluxo das informações 
entre a poder público municipal e os usuários geradores de RCC na cidade de São Paulo.

A linha do estudo foram as empresas transportadoras de caçambas com o uso de caminhões poliguindastes, os locais de destinação como as áreas de transbordo e triagem para resíduos da construção civil (ATTs), assim como os Ecopontos, áreas para destinação de volumes até $1,0 \mathrm{~m}^{3}$ usuário dia, gerados no município de São Paulo.

\subsection{Pesquisa nos canais de comunicação: sites da PMSP/SES/ AMLURB}

Buscou-se esclarecer com esse trabalho se as informações disponíveis nos sites oficiais da Prefeitura e da Secretaria de Serviços (AMLURB) sobre gestão de Resíduos da Construção Civil no município permitiam, de fato, aos usuários o contato com as empresas transportadoras de RCC e, consequentemente, o destino adequado, ou seja, se haviam dados consistentes e atualizados para o acesso do usuário gerador.

Com relação ao transporte de RCC via caçambas estacionárias, foram pesquisadas as seguintes informações, consideradas mais relevantes à integração do usuário ao sistema:

- Classes de RCC que podem ser transportados;

- Volume a ser transportado;

- Presença de documentação necessária (CTR);

- Dados para contato: endereço, telefone, nome da empresa.

Para os locais de recebimento de RCC, as ATTs e os Ecopontos, foram consideradas as seguintes informações:

- Classes de RCC que podem ser destinados;

- Forma e volume a serem entregues;

- Documentação necessária para a entrega/recebimento (CTR);

- Dados para contato: endereço, telefone, nome da empresa. 


\section{RESULTADOS E DISCUSSÕES}

Para que o sistema geração, transporte, destinação e fiscalização de RCC funcione, ou seja, para que todos os participantes cumpram a sua parte no processo, é imprescindível que os dados apresentados nos canais de informações e nas listas oficiais da PMSP cheguem aos atores de forma atualizada e acessível.

Os dados coletados nos canais de comunicação da PMSP/SES/ AMLURB com a população trazem informações sobre as empresas de transporte de RCC via caçambas estacionárias, com o uso de caminhões poliguindastes, e os locais de destinação, sendo eles as áreas de transbordo e triagem de resíduos da construção civil (ATTs) e os Ecopontos, locais para entrega voluntária de pequenos volumes, até $1,0 \mathrm{~m}^{3}$ usuário /dia, que servem aos geradores de pequenos volumes de RCC.

\section{a) Pesquisas nos canais de comunicação: sites da PMSP/ SES/} AMLURB.

Esta pesquisa foi realizada em relação às empresas de transporte via caçambas estacionárias com o uso de caminhões poliguindastes. O processo de divulgação das empresas autorizatárias de transporte de RCC é feito através de listas que são acessadas por links nos sites. Através da busca nesses links das empresas de transporte de RCC, foram encontradas quatro listas nos sites da AMLURB e da PMSP.

Na lista 1, que se refere às Empresas que prestam serviços de coleta e transporte de resíduos da construção civil, atualizada em 16/08/2016, houve um total de 11 páginas e aproximadamente 1.450 contatos (PMSP, 2016c). Na lista 2, que se refere às Empresas que prestam serviços de coleta e transporte de resíduos da construção civil, atualização em 17/03/2016, houve um total de 72 páginas e aproximadamente 2.600 contatos (PMSP, 2016d). Na lista 3, referente a Empresas que prestam serviço para grandes geradores de resídu- 
os, atualizada em 17/03/2016, havia três páginas com 111 contatos (PMSP, 2016e). Já a lista 4, referente a Empresas que prestam serviço para grandes geradores de resíduos, atualizada em 17/03/2016, houve três páginas com 111 contatos (PMSP, 2016f).

Em ambas as listas 1 e 2 foram apresentadas as seguintes informações:

- $N^{\circ}$ de cadastro, razão social /nome, endereço, responsável, datas de publicação / vencimento, situação cadastral e telefone.

As listas 3 e 4 são idênticas e, em ambas, foram encontradas informações como:

- $N^{\circ}$ de cadastro, razão social / nome, endereço e telefone de empresas de transporte de resíduos para grandes geradores.

A pesquisa das listas nos sites da PMSP/SES/AMLURB foi trabaIhosa, visto que havia duas listas com o mesmo título, porém com atualizações diferentes. Isto pode levar a uma confusão das informações.

O entendimento para a definição das listas consultadas, conforme a classificação dos RCC a serem transportados, não foi fácil. Foi necessária a consulta ao Decreto n. 46.594, de 3 de novembro de 2005, que "regulamenta a coleta, o transporte, o tratamento e a disposição final de resíduos inertes, de que trata a lei n. 13.478, de 30 de dezembro de 2002, com as alterações subsequentes" (SÃO PAULO, 2005).

Assim, pode-se concluir que as listas 1 e 2 disponíveis nos sites referem-se exclusivamente às empresas regularizadas na PMSP e que realizam o transporte de resíduos sólidos inertes, ou seja, os resíduos classe II B, conforme classificação da NBR 10004 (ABNT, 2004b). As listas 3 e 4 são para o transporte de resíduos sólidos de modo geral.

Identifica-se, portanto, que não há um padrão adotado pela PMSP referente a conceitos importantes na gestão de RCC como a classificação e definição dos resíduos da Construção Civil. A PMSP adota a classificação da NBR 10004:2004 e não a CONAMA 307 e 
suas atualizações, sendo esta última uma Norma Federal e específica para os RCC.

Também faltaram informações importantes como o endereço da garagem, item que proporcionaria ao gerador a possibilidade de saber qual a distância do ponto de saída do transporte até o ponto de chegada no local de geração, dado esse que permitiria uma tomada de decisão quanto à empresa a ser contratada em relação à distância do ponto de geração de RCC ao local de saída das caçambas.

b) Busca por dados para que o usuário gerador possa utilizar o sistema de transporte:

Dentre os dados obtidos, considerados essenciais para que o usuário gerador possa utilizar o sistema de transporte, ficou claro no site que os resíduos não perigosos e não inertes, classes II B, devem ser transportados pelas empresas pertencentes as Listas 1 e 2. Porém não menciona ou faz relação aos RCC classe A, conforme classificação CONAMA n. 307 e alterações. Além disso, não houve clareza suficiente nas informações para o gerador acionar uma lista específica de empresas que transportem os RCC classes B e C, visto que as listas 3 e 4 são para grandes geradores de resíduos e não especificam a classe destes.

Também não foram encontradas informações sobre empresas especializadas no transporte de resíduos classe D. Foi recomendado, em contato via telefone com a AMLURB, procurar a Companhia Ambiental do Estado de São Paulo (CETESB). Ressalta-se que, até $50 \mathrm{~kg} /$ diários de resíduos inertes por dia, a PMSP faz a coleta e transporte, desde que estes estejam bem acondicionados, conforme a Lei Municipal n. 13.478 de 2002, atualizada pela Lei Municipal de São Paulo n. 13.522, de 19 de fevereiro de 2003, em seu artigo 22. Para os demais volumes transportados, o procedimento fica vinculado à capacidade das caçambas estacionárias autorizatárias que podem variar de 3,0 a 5,0 $\mathrm{m}^{3}$. 
Há dados sobre os RCC no site da AMLURB no link - ENTULHO, referente ao documento CTR, porém essa informação quanto à necessidade de contratação dos serviços de transporte de RCC, sua implicância legal e a corresponsabilidade entre os atores no processo não aparece vinculada às listas das empresas autorizatárias ao transporte de RCC, ou seja, as listas apresentam apenas a regularidade da empresa frente ao cadastro na PMSP. Segundo Schneider (2003), o cadastramento de uma empresa transportadora no órgão gestor municipal não garante a deposição regular do RCC recolhido.

\section{c) Áreas de destinação de RCC em ECOPONTOS e ATTs}

Para os locais de destinação e recebimento de RCC, Ecopontos e ATTs, foi possível localizar as informações com facilidade através dos sites da PMSP/SES/AMLURB, que apresentam dados atualizados, dispostos de modo organizado em listas. Os endereços dos Ecopontos foram obtidos no site da PMSP/AMLURB. Quanto aos números dos telefones de contato, não houve referências para cada unidade, e o contato foi obtido através de uma central de atendimento 156, que forneceu informações sobre a rede.

De forma explorativa, algumas perguntas foram realizadas para a central 156, para checagem das informações obtidas pelos sites, como endereço e horário de funcionamento. Também foram solicitadas informações complementares como o recebimento de RCC perigosos e o destino dos rejeitos. Como resultado, obteve-se que os endereços estão atualizados no site da Prefeitura de São Paulo; as classes de RCC recebidos, segundo o site, aceitam entulhos, resíduos recicláveis, além dos volumosos como os móveis; a forma, condições e volume máximo, de acordo com o site, a entrega é voluntária sem custo ao gerador e recebem 1,0 metro cúbico/usuário/dia; o recebimento de RCC classe D, perigosos foi informado que não é permitido receber esses resíduos, a exemplo de amianto, lâmpadas e tintas; os rejeitos 
são encaminhados aos aterros sanitários; todos os Ecopontos funcionam de segunda a sábado, das $6 \mathrm{~h}$ às $22 \mathrm{~h}$, e aos domingos e feriados, das $6 \mathrm{~h}$ às $18 \mathrm{~h}$. As informações obtidas na central 156 estão de acordo com as obtidas pela pesquisa realizada nos sites, porém, quanto aos dados referentes ao recebimento dos RCC classe D perigosos, são divergentes em relação ao Decreto Municipal n. 42.217, de 24 de julho de 2002, que cita não ser permitido o recebimento de cargas de resíduos de construção civil constituídas predominantemente por RCC classe I perigosos, sendo que os Ecopontos, conforme as informações coletadas, não aceitam esse tipo de resíduo.

\subsection{Dados sobre as ATTs}

As listas com os nomes, endereços e telefones das ATTs constam do site da PMSP/SES/AMLURB e seu acesso foi fácil, inclusive com explicações sobre o que é uma ATT e seu funcionamento. Porém as informações como os telefones, horários de atendimento e quais classes de RCC recebem não são mencionados, o que distancia ainda mais o gerador às áreas de destino de seus resíduos, visto que o poder de decisão sobre o local de destinação fica por conta das empresas transportadoras que realizam o preenchimento da documentação CTR. Essa situação prorroga uma evolução do processo em que o usuário gerador possa escolher para onde o seu RCC deva ser destinado, considerando os critérios de distância do ponto gerador, impacto ao meio e valor agregado.

Dessa forma, foi realizado contato com as ATTs, Correia LTDA localizada na Avenida Doutor Ulisses Guimarães, 3947, Vila Nogueira, Diadema, telefone: 4075-3724, e a ATT PARI Maxxipappel Comércio de Aparas e Sucatas, na Rua Joaquim Carlos, 870, Pari, São Paulo, telefone 2618-1384, para a obtenção de mais informações.

Nessa consulta, notou-se que: 
- Os telefones e endereços retirados do site da Prefeitura estão atualizados;

- As ATT's recebem e separam os RCC que chegam misturados nas caçambas e destinam de forma adequada, ou seja, os RCC de origem mineral (concreto, argamassa, alvenaria etc.) são encaminhados para aterros de inertes, para aterros da construção civil e para as Usinas Recicladoras. O resíduo reaproveitável para reciclagem é comercializado;

- Não recebem resíduos classe D (perigosos);

- Não existe um volume máximo para entrega e normalmente aceitam no mínimo uma caçamba por gerador;

- O recebimento do RCC deve ser acompanhado da documentação prevista em lei, o CTR;

- O RCC recolhido é separado por sua tipologia, e o rejeito é levado para aterros sanitários, todos obrigatoriamente licenciados pelos órgãos competentes;

- Horário de funcionamento, normalmente das $7 \mathrm{~h}$ às $17 \mathrm{~h}$, de segunda a sexta - feira e sábados de $7 \mathrm{~h}$ às $13 \mathrm{~h}$, podendo variar de empresa para empresa.

\section{CONCLUSÕES}

As listas disponíveis aos usuários, principalmente aos geradores de pequenos volumes de RCC, não estão claras e são conflitantes, o que impede que os usuários, sejam eles grandes ou pequenos geradores, se integrem de fato ao sistema de gestão de resíduos da construção civil da cidade de São Paulo, de forma participativa e sustentável.

Há listas com o mesmo título, porém, com atualizações diferentes. Caso o contribuinte consulte essas listas para a contratação de um serviço de transporte de RCC, ele terá muita dificuldade para escolher a adequada. Os títulos das listas, além de serem conflitan- 
tes, não indicam a classe do resíduo a ser transportado. O gerador também não dispõe de informações suficientes para o transporte e destinação dos demais RCC, ou seja, não há indicação clara nas listas para as classes B e C, e não há informações sobre os classe D, perigosos. Os dados sobre as ATTs estão claros quanto aos endereços, porém não há informações sobre a forma, a classe e documentação dos RCC recebidos.

As informações disponibilizadas nos sites da PMSP são insuficientes e, por isso, não situam o contribuinte quanto a sua participação no processo de geração, transporte, destinação e fiscalização de RCC. Não fica clara a sua importância como ator protagonista do sistema, no qual as suas tomadas de decisão podem indicar as quantidades, as classes de RCC transportadas e destinadas e até mesmo se o fluxo migrará para a ilegalidade, através da contratação de empresas não autorizatárias e descarte em locais inadequados.

Portanto é fundamental uma remodelagem da forma como o município disponibiliza as informações sobre RCC, sendo necessário uma linguagem mais simples, clara, atualizada e direta para a integração dos usuários ao sistema de gestão de resíduos da construção civil, o que deveria ser seguido por outros municípios brasileiros, contribuindo assim, para uma redução do descarte inadequado de RCC no âmbito do espaço urbano.

\section{REFERÊNCIAS}

ANGULO, S. C. et al. Caracterização de agregados de resíduos de construção e demolição reciclados separados por líquidos densos. In: CONFERÊNCIA LATINO-AMERICANA DE CONSTRUÇÃO SUSTENTÁVEL, 1.; ENCONTRO NACIONAL DE TECNOLOGIA DO AMBIENTE CONSTRUÍDO, 10., São Paulo, 2004. Anais... São Paulo: PCC/USP, 2004. Disponível em: <http://www. reciclagem.pcc.usp.br/ftp/caract_liquidos\%20densos_angulo\%20et\%20al. pdf>. Acesso em: 15 jun. 2016. 
ASSOCIAÇÃO BRASILEIRA DE NORMAS TÉCNICAS (ABNT). NBR 15112, de 30 de junho de 2004. Fixa os requisitos mínimos exigíveis para projeto, implantação e operação de áreas de reciclagem de resíduos sólidos da construção civil classe A. Rio de Janeiro: ABNT, 2004a.

. NBR 10004, de 31 de maio de 2004. Classificação de Resíduos Sólidos. Rio de Janeiro: ABNT, 2004b.

BRASIL. Resolução CONAMA n. 469, de 29 de julho de 2015. Altera a Resolução CONAMA n. 307, de 5 de julho de 2002, que estabelece diretrizes, critérios e procedimentos para a gestão dos resíduos da construção civil. Disponível em: <http://www.mma.gov.br/port/conama/legiabre.cfm?codlegi=714>. Acesso em: 4 nov. 2016.

- Secretaria de Assuntos Estratégicos, Instituto de Pesquisa e Economia Aplicada (IPEA). Relatório de Pesquisa Diagnóstico dos Resíduos Sólidos da Construção Civil. Brasília, 2012. Disponível em: <http://www.ipea. gov.br/agencia/images/stories/PDFs/relatoriopesquisa/120911_relatorio_ construcao_civil.pdf>. Acesso em: 17 jun. 2016.

Resolução CONAMA n. 448, de 19 de janeiro de 2012. Altera os

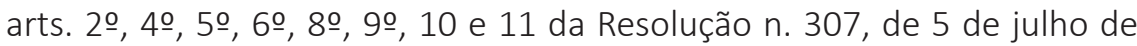
2002, do Conselho Nacional do Meio Ambiente-CONAMA. Disponível em: <http://www.mma.gov.br/port/conama/legiabre.cfm?codlegi=672>. Acesso em: 4 nov. 2016.

. Resolução CONAMA n. 431, de 24 de maio de 2011. Altera o art. 3ㅇ da Resolução n. 307, de 5 de julho de 2002, do Conselho Nacional do Meio Ambiente-CONAMA, estabelecendo nova classificação para o gesso. Disponível em: <http://www.mma.gov.br/port/conama/legiabre. cfm?codlegi=649>. Acesso em: 4 nov. 2016.

. Lei n. 12.305, de 2 de agosto de 2010. Institui a Política Nacional de Resíduos Sólidos; altera a Lei n. 9.605, de 12 de fevereiro de 1998; e dá outras providências. Disponível em: <http://www.planalto.gov.br/ccivil_03/ ato2007-2010/2010/lei/l12305.htm>. Acesso em: 10 nov. 2016.

. Resolução CONAMA n. 348, de 16 de agosto de 2004. Altera a Resolução CONAMA n. 307, de 5 de julho de 2002, incluindo o amianto na classe de resíduos perigosos. Disponível em: <http://www.mma.gov.br/port/ conama/legiabre.cfm?codlegi=449>. Acesso em: 4 nov. 2016. 
Transporte e destinação dos RCC gerados no Município de São Paulo: a importância da qualidade das informações disponibilizadas aos usuários

. Resolução CONAMA n. 307, de 5 de julho de 2002. Estabelece diretrizes, critérios e procedimentos para a gestão dos resíduos da construção civil. Disponível em: <http://www.mma.gov.br/port/conama/ legiabre.cfm?codlegi=307>. Acesso em: 4 nov. 2016.

JACOBI, P. R.; BESEN, G. R. Gestão de resíduos sólidos em São Paulo: desafios da sustentabilidade. Estudos Avançados, São Paulo, v. 25, n. 71, p. 135-158, jan./abr. 2011.

PASCHOALIN, F. J. A.; GRAUDENZ, G. S. Destinação irregular de resíduos de construção e demolição (RCD) e seus impactos na saúde coletiva. Revista de Gestão Social e Ambiental, São Paulo, v. 6, n. 1, p. 127-142, jan./abr. 2012.

PINTO, T. P. Metodologia para a gestão diferenciada de resíduos sólidos da construção urbana. 1999. Tese (Doutorado em Engenharia) - Escola Politécnica da Universidade de São Paulo (USP), São Paulo, 1999.

PREFEITURA DE SÃO PAULO (PMSP). Áreas de destinação dos resíduos da construção civil (RCC). Área de Transbordo e Triagem (ATT). São Paulo, 2016a. Disponível em: <http://www.prefeitura.sp.gov.br/cidade/secretarias/ servicos/amlurb/att/index.php?p=4632>. Acesso em: 12 nov. 2016.

. ECOPONTO - Estação de Entrega Voluntária de Inservíveis. São Paulo, 2016b. Disponível em: <http://www.prefeitura.sp.gov.br/cidade/ secretarias/servicos/amlurb/ecopontos/index.php?p=4626>. Acesso em: 12 nov. 2016.

. Empresas cadastradas: empresas que prestam serviços de coleta e transporte de resíduos da construção civil - lista 1. 16 ago. 2016c. Disponível em: <http://www.prefeitura.sp.gov.br/cidade/secretarias/upload/Entulho. pdf>. Acesso em: 25 nov. 2016.

- Empresas cadastradas: empresas que prestam serviços de coleta e transporte de resíduos da construção civil- lista 2. 17 mar. 2016d. Disponível em: <http://www.prefeitura.sp.gov.br/cidade/secretarias/upload/entulho_ site_17_03_16.pdf>. Acesso em: 25 nov. 2016.

. Empresas cadastradas: empresas que prestam serviço para grandes geradores de resíduos - lista 3. 17 mar. 2016e. Disponível em: <http://www. prefeitura.sp.gov.br/cidade/secretarias/upload/transportadores_GGRS_ marco_16.pdf>. Acesso em: 25 nov. 2016. 
. Empresas cadastradas: empresas que prestam serviços para grandes geradores de resíduos- lista 4. 17 mar. 2016f. Disponível em: <http://www. prefeitura.sp.gov.br/cidade/secretarias/upload/transportadores_GGRS_ marco_16.pdf>. Acesso em: 25 nov. 2016.

- Autoridade Municipal da Limpeza Urbana - AMLURB. Gestão de resíduos da construção civil RCC - Controle de Transporte de Resíduos C.T.R. Implementação do Formulário Eletrônico. Apresentação- Autoridade Municipal de Limpeza. São Paulo: Prefeitura Municipal de São Paulo, 2015.

. PGIRS - Plano de Gestão Integrada de Resíduos Sólidos da Cidade de São Paulo. São Paulo: Secretaria de Serviços, 2014. Disponível em: <http:// www.prefeitura.sp.gov.br/cidade/secretarias/upload/servicos/arquivos/ PGIRS-2014.pdf>. Acesso em: 23 set. 2015.

SÃO PAULO, Município [de]. Decreto n. 46.594, de 3 de novembro de 2005. Regulamenta a coleta, o transporte, o tratamento e a disposição final de resíduos inertes, de que trata a lei n. 13.478, de 30 de dezembro de 2002, com as alterações subsequentes. Disponível em: <http://www3. prefeitura.sp.gov.br/cadlem/secretarias/negocios_juridicos/cadlem/integra. asp?alt=04112005D\%20465940000 >. Acesso em: 12 nov. 2016.

. Lei n. 13.478, de 30 de dezembro de 2002. Dispõe sobre a organização do sistema de limpeza urbana do município de São Paulo; cria e estrutura seu órgão regulador; autoriza o poder público a delegar a execução dos serviços públicos mediante concessão ou permissão; institui a Taxa de Resíduos Sólidos Domiciliares- TRSD, a Taxa de Resíduos Sólidos de Serviços de Saúde- TRSS e a Taxa de Fiscalização dos Serviços de Limpeza Urbana- FISLURB; Cria o Fundo Municipal de Limpeza Urbana- FMLU, e dá outras providências. 2002a. Disponível em: <http://www.prefeitura.sp.gov. br/cidade/secretarias/subprefeituras/upload/pinheiros/arquivos/Lei_13478. pdf>. Acesso em: 12 jul. 2016.

. Decreto n. 42.217, de 24 de julho de 2002. Regulamenta a Lei n. 10.315, de 30 de abril de 1987, no que se refere ao uso de áreas destinadas ao transbordo e triagem de resíduos de construção civil e resíduos volumosos, na forma que especifica, e dá outras providências. Disponível em: <www.prefeitura.sp.gov.br/cidade/secretarias/upload/Decreto42217-1. $r t f>$. Acesso em: 12 nov. 2016. 
. Decreto n. 37.952, de 11 de maio de 1999. Regulamenta a coleta, o transporte e a destinação final de entulho, terras e sobras de materiais de construção, de que trata a Lei n. 10.315, de 30 de abril de 1987, e dá outras providências. Disponível em: <http://webcache.googleusercontent. com/search?q=cache:qCWFTDialkoJ:ww2.prefeitura.sp.gov.br/arquivos/ secretarias/servicoseobras/projetos/ecoponto/0001/Decreto37952. $r t f+\& c d=2 \& h l=p t-B R \& c t=c l n k \& g l=b r>$. Acesso em: 12 nov. 2016.

SCHMITZ, S.; VIANA, E. Gestão dos resíduos da construção civil no litoral do Estado do Paraná. Revista Brasileira de Gestão Ambiental e Sustentabilidade, João Pessoa, PB, v. 2, n. 3, p. 153-165, 2015.

SCHNEIDER, D. M. Deposições irregulares de resíduos da construção civil na cidade de São Paulo. 2003. 131p. Dissertação (Mestrado em Saúde Pública) - Escola Politécnica da Universidade de São Paulo (USP), São Paulo, 2003.

SINDICATO DA INDÚSTRIA DA CONSTRUÇÃO CIVIL (SINDUSCON). Gestão Ambiental de Resíduos da Construção Civil- A experiência do Sinduscon-SP: manual técnico. São Paulo, 2005. 
